\title{
Kohärenz im Internationalen Privat- und Verfahrensrecht der Europäischen Union
}

\author{
Hrsg. v. Jan von Hein u. Giesela Rühl
}

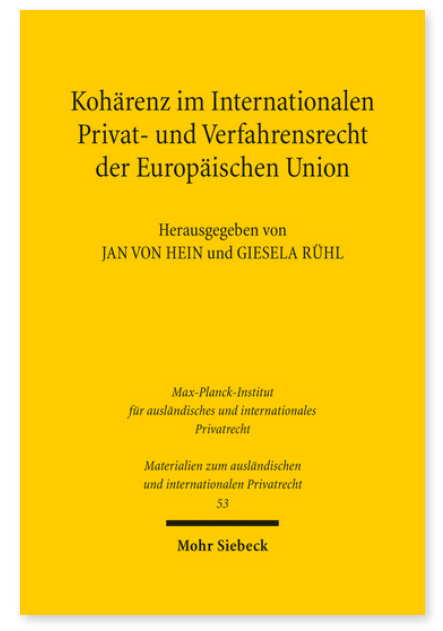

2016. XVII, 389 Seiten. MatIPR 53

ISBN 978-3-16-154197-1

DOI 10.1628/978-3-16-154197-1

eBook PDF $94,00 €$

ISBN 978-3-16-153350-1

Leinen $94,00 €$
Seit der Verabschiedung des Vertrags von Amsterdam im Jahre 1997 hat die Europäische Union eine Vielzahl von Verordnungen auf dem Gebiet des Internationalen Privat- und Verfahrensrechts erlassen. Die daraus resultierenden Probleme der konsistenten Auslegung und wechselseitigen Abstimmung dieser Instrumente waren Gegenstand einer Konferenz, die im Oktober 2014 in Freiburg i.Br. stattfand. Die dort gehaltenen Referate sind in dem vorliegenden Band versammelt. Sie arbeiten Wertungswidersprüche zwischen den verschiedenen Rechtsakten heraus, beleuchten die Rahmenbedingungen für eine kohärentere Regelung und zeigen Perspektiven für eine mögliche Kodifikation des europäischen Internationalen Privat- und Verfahrensrechts auf. Zudem enthält der Band englische Zusammenfassungen der gehaltenen Referate sowie ausführliche Diskussionsberichte.

Inhaltsübersicht

\section{Teil 1: Grundlagen}

Jürgen Basedow: Kohärenz im Internationalen Privat- und Verfahrensrecht der Europäischen Union: Eine einleitende Orientierung - Anatol Dutta: Gemeinsame oder getrennte Kodifikation von IPR und IZVR auf europäischer Ebene: Die bisherigen und geplanten Verordnungen im Familien- und Erbrecht als Vorbilder für andere Rechtsgebiete? - Thomas Kadner Graziano: Gemeinsame oder getrennte Kodifikation von IPR und IZVR: Das schweizerische IPR-Gesetz als Modell für eine europäische Gesamtkodifikation - Lehren für die EU?

Teil 2: Der räumliche Anwendungsbereich des europäischen IPR/IZVR

Burkhard Hess: Binnenverhältnisse im Europäischen Zivilprozessrecht: Grenzüberschreitende v. nationale Sachverhalte Tanja Domej: Das Verhältnis nach »außen«: Europäische v. Drittstaatensachverhalte - Andrea Schulz: Die EU und die Haager Konferenz für Internationales Privatrecht

Teil 3: Subjektive und personale Anknüpfungspunkte im euro-päischen IPR/IZVR

Felix Maultzsch: Parteiautonomie im Internationalen Privat- und Zivilverfahrensrecht - Frauke Wedemann: Die Verortung juristischer Personen im europäischen IPR und IZVR - Brigitta Lurger: Die Verortung natürlicher Personen im europäischen IPR und IZVR: Wohnsitz, gewöhnlicher Aufenthalt, Staatsangehörigkeit

Teil 4: Objektive Anknüpfungsmomente für Schuldverhältnisse im europäischen IPR/IZVR

Michael Müller: Objektive Anknüpfungsmomente für Schuldverhältnisse im europäischen IPR und IZVR: Die Behandlung vertraglicher Sachverhalte - Haimo Schack: Kohärenz im europäischen Internationalen Deliktsrecht

Teil 5: Schutz schwächerer Parteien und von Allgemein-interessen im europäischen IPR/IZVR

Eva-Maria Kieninger: Der Schutz schwächerer Personen im Schuldrecht - Urs Peter Gruber: Der Schutz schwächerer Personen im Familien- und Erbrecht - Moritz Renner: Ordre public und Eingriffsnormen: Konvergenzen und Divergenzen zwischen IPR und IZVR

Jan von Hein ist Professor für Bürgerliches Recht, Internationales Privatrecht und Rechtsvergleichung sowie Direktor am Institut für ausländisches und internationales Privatrecht, Abt. III, an der Universität Freiburg i. Br.

Giesela Rühl ist Inhaberin des Lehrstuhls für Bürgerliches Recht, Zivilverfahrensrecht, Europäisches und Internationales Privat- und Verfahrensrecht und Rechtsvergleichung an der Humboldt-Universität zu Berlin.

Jetzt bestellen:

https://mohrsiebeck.com/buch/kohaerenz-im-internationalen-privat-und-verfahrensrecht-der-europaeischen-union9783161541971?no_cache=1

order@mohrsiebeck.com

Telefon: +49 (0)7071-923-17

Telefax: $+49(0) 7071-51104$ 